\title{
Normocellular CSF in herpes simplex encephalitis
}

\author{
Abhinbhen W. Saraya ${ }^{1 *}$, Supaporn Wacharapluesadee ${ }^{1}$, Sininat Petcharat ${ }^{1}$, Nuntaporn Sittidetboripat ${ }^{1}$, \\ Siriporn Ghai ${ }^{1}$, Henry Wilde ${ }^{1,2}$ and Thiravat Hemachudha ${ }^{1}$
}

\begin{abstract}
Background: Herpes simplex virus (HSV) is the most common cause of sporadic encephalitis worldwide. The high mortality rate (70-80 \%) of herpes simplex encephalitis (HSE) can be reduced to 20-30\% by antiviral therapy. However, normocellular CSF can lure physicians to look for non-infectious causes, resulting in delayed treatment. This study aimed to investigate, characterize and differentiate HSE patients, with normocellular and pleocytosis CSF, according to neuroimaging patterns, underlying disease, CSF viral load and clinical outcome. Patients with proven (by PCR positive CSF) or presumed viral infections of the CNS admitted to King Chulalongkorn Memorial Hospital between January 2002 and 2011 were analyzed.
\end{abstract}

Results: HSV was detected in the CSF of 43 patients but only 23 patients had encephalitis. Among these 23 patients, 6 cases (26.1\%) had normal CSF WBC $\left(<5\right.$ cells $\left./ \mathrm{mm}^{3}\right)$. One patient in this normocellular CSF group had HIV infection. Although this patient had low CD4 counts $\left(<200 \mathrm{cell} / \mathrm{s} / \mathrm{mm}^{3}\right)$, the peripheral WBC counts showed only mild leukopenia. The CSF HSV viral load in the pleocytosis group was higher than the normocellular group, with an average of 12,200 vs 3027 copies/ml respectively. There was no correlation between the viral load and the clinical outcome. With respect to neuroimaging, 4 (66.7\%) patients in the normocellular group had unremarkable/non-specific results.

Conclusions: Normocellular CSF in HSE is not rare, and can be seen in normal as well as immunocompromised hosts. Clinicians should not exclude CNS infection, especially HSE, merely based on the absence of CSF pleocytosis and/or unremarkable neuroimaging study.

Keywords: Encephalitis, Viral encephalitis, Herpes simplex encephalitis, Herpes simplex virus

\section{Background}

Herpes simplex encephalitis (HSE) caused by herpes simplex virus (HSV) is the most common sporadic viral encephalitis among adults worldwide [1, 2]. It has been responsible for up to $20 \%$ of viral encephalitis cases [3]. This disease has a bimodal distribution, where onethird of the patients are under the age of 20 , while the remaining are over the age of 50 [4]. Peak incidence is around 60-64 years of age. Neither gender, season, nor immune status of a patient affects its occurrence. The

\footnotetext{
*Correspondence: abhinbhen@gmail.com

${ }^{1}$ WHO-CC for Research and Training on Viral Zoonoses, Division of Neurology, Department of Medicine, Faculty of Medicine,

Neuroscience Centre for Research and Development, Chulalongkorn

University and King Chulalongkorn Memorial Hospital, Rama 4 Road,

Pathumwan, Bangkok 10330, Thailand

Full list of author information is available at the end of the article
}

high mortality rate of HSE (70-80 \%) can be reduced to $20-30 \%$ by acyclovir therapy. Acyclovir should be taken within 2 days of neurological symptom's onset as delayed treatment can result in severe morbidity and mortality in approximately one-third of the patients $[5,6]$.

HSV-1 is responsible for more than $90 \%$ of HSE in adults [7]. Recent studies have demonstrated many cases of HSE that resulted from HSV-2 [8, 9]. HSV can also be associated with myelitis, radiculitis or both. HSV's preferred areas are the limbic structures, the medial temporal cortex and the orbito-frontal regions, which are all innervated by branches of olfactory and trigeminal nerves. HSV is contracted via contact with the mucosal surface of mouth, eye or genitalia, and has been speculated to subsequently enter the CNS via any nearby sensory nerve ending into these nerves and the 
corresponding ganglia. Viral entry into the CNS via olfactory tract has been substantiated by numerous animal experiments $[10,11]$. However, the neuropathology of a mouse brain is more diffused compared to the welldefined fronto-temporal distribution in a human brain.

HSV can reside in the nerve and can either replicate or establish a latent infection [1]. Its DNA can be detected in the trigeminal ganglion of previously infected patients. At the time of reactivation, latent HSV in the trigeminal ganglia can travel along the tentorial nerve that innervates the meninges of the anterior and the middle cranial fossa. HSV genomes have also been found in olfactory bulb, pons, and the medulla of autopsied brains of normal individuals [12]. Early gross brain pathology of most HSE cases showed hemorrhagic necrosis of the medial or the inferior temporal lobe. These lesions were mainly bilateral and asymmetrical in distribution. Sub-frontal and insular regions were damaged in the latter phase [13]. Brain parenchyma in such regions of HSE patients, who died after 2 weeks of exhibiting HSE, revealed liquefaction necrosis.

The cerebral inflammation from glial cells activation, due to the presence of HSV, includes increase in expression of pattern recognition receptors, especially Toll-like receptors (TLRs) and interferon regulatory factors (IRFs) [4]. Genetic factors, such as deficiency of Toll-like receptor-3 (TLR3), can predispose an individual (especially children and young adults) to HSE $[10,11,14]$. Mutation of TLR3 and TLR3 pathway genes such as UNC93B1, TRIF, TRAF3, and TBK1 can result in the defective production of interferon (IFN). Insufficient amount of IFN- $\beta$ and IFN- $\lambda$ leads to an increase in viral replication and enhances cell death. Relapse of HSE tends to occur more frequently in those with abnormal TLR3 immunity. However, these mutations were attributed to only $5 \%$ of HSE in children and young adults [11].

The characteristic symptoms of HSE are abnormal behavior/psychosis (66 \%), confusion/disorientation (81\%) and speech disturbance (66\%), which are justifiable due to the preferential involvement of the frontal and temporal lobes. Other symptoms of HSE include fever (76-90\%), headache (70-90\%) and seizure (50-55\%) $[5,15]$. However, these symptoms are not unique as they can be present in encephalitis caused by other viruses $[16,17]$. Moreover, these symptoms can also be found in immune-mediated encephalitis, in particular the antiNMDA receptor encephalitis, which can mimic or occur as a relapse encephalitis after the first episode of HSE [18].

Hence, diagnosis of HSE requires an integration of clinical presentations, neuroimaging, and laboratory tests, especially molecular diagnostic techniques. The current gold standard confirmatory test for HSE is polymerase chain reaction (PCR) to detect HSV DNA in the CSF, whose sensitivity is approximately $96 \%$ with a specificity of $99 \%$ in experienced laboratories [19]. For high accuracy of PCR, specimens should be analyzed within 2-10 days after neurological onset [2].

HSE patients are presumed to have evidence of inflammatory response in CNS such as CSF pleocytosis or abnormal neuroimaging. CSF pleocytosis in HSE has been found in more than $90 \%$ of the patients, with an average WBC count of $100-200$ cells $/ \mathrm{mm}^{3}[2,20]$. Majority of the cases $(80 \%)$ had mild to moderately elevated CSF protein levels $(\sim 100 \mathrm{mg} / \mathrm{dl})$, with normal glucose. Detection of red blood cells in the CSF was not an indicator of HSV associated CNS infection [19], but may represent a poor predictor [21]. CSF examination by real-time PCR to detect HSV DNA was validated as a new gold standard for the diagnosis of HSE in 2004 [2, 19, 22]. However, its value in determining viral amount has been controversial [21]. Further, there have been increasing case reports of normal WBC counts (either normocellular or acellular) in the CSF of normal and immunocompromised HSE patients, and some were associated with unremarkable/nonspecific magnetic resonance imaging (MRI) findings [15-17, 23].

\section{Methods}

Patients with proven (by PCR positive CSF) or presumed viral infections of the CNS admitted to King Chulalongkorn Memorial Hospital (KCMH), Bangkok, Thailand, between January 2002 and 2011 were analyzed. Encephalitis was defined as clinical evidence of brain parenchymal dysfunction [6], which could not be explained by metabolic, electrolyte imbalance, bleeding disorders or systemic immune disorders such as systemic lupus erythematosus (SLE), Behcet's disease or Sjogren syndrome. Bacterial, Rickettsial, fungal, tuberculosis and parasitic causes were excluded by appropriate clinical and laboratory examinations. The diagnosis of HSE was based on the clinical features of encephalitis with the exclusion of other mimics as described above, and the presence of HSV DNA in the CSF.

Retrospective study included those admitted in the years 2002-2009 which did not require ethical approval or written informed consent based on $\mathrm{KCMH}$ ethics committee IRB 986/2555. Study on patients admitted in the years 2010-2011 was approved by the $\mathrm{KCMH}$ ethics committee (Reference no. 015/2011). Informed consent was obtained from these patients in written form; in cases where the patient was unable to communicate or was underage, consent (and assent where applicable) was obtained from a family member, parent or guardian. 
All encephalitis patients with presumed viral causes had their CSF examined by PCR for HSV, Varicella zoster virus (VZV), Epstein-Barr virus (EBV), Cytomegalovirus (CMV) and enteroviruses. Paraneoplastic and autoimmune panels as previously described [24] were tested in one retrospective patient with normocellular CSF and unremarkable brain MRI examination.

\section{PCR technique for HSV DNA}

Qualitative real-time PCR [25] was performed on specimens before 2006, where $5 \mu \mathrm{l}$ of extracted DNA was used for amplification and detection. Specimens received year 2007 onwards, quantitative assay was performed using artus $^{\circledR}$ HSV-1/2 LC PCR kit (Qiagen Inc., Valencia, CA, USA). DNA from 0.1 to $1 \mathrm{~mL}$ of CSF was extracted using Nuclisens ${ }^{\circledR}$ extraction kit (bioMérieux, Boxtel, The Netherlands). The amplification was undertaken using a LightCycler ${ }^{\circledR}$ instrument (Roche Diagnostics, Germany). HSV-1 and -2 DNA PCR product was differentiated by melting curve analysis in the LightCycler ${ }^{\circledR}$ PCR instrument. The standard curve was generated from four quantitation standards of HSV (10, 100, 1000 and 10,000 copies $/ \mu \mathrm{l}$ ) supplied by the manufacturer. Preparation of PCR assay, PCR profile and data analysis was conducted according to the manufacturer's protocol. The internal control supplied by the manufacturer was included in all reactions to check for possible PCR inhibition. The analytical detection limit of the PCR Kit was $1 \mathrm{copy} / \mu \mathrm{l}$ $(\mathrm{p}=0.05)$ (Qiagen Inc., CA, USA). For qualitative assay, all steps were the same as quantitative assay, except that the standard curve was not used for calculation, and only one standard positive control was performed along with the assayed sample.

\section{Results}

\section{Patient data}

There were 413 patients with viral neurological infections during the 10-year period. All had lymphocytic predominance with normal glucose CSF profile. Those with normal CSF cell count were considered encephalitic only when their brain dysfunctions could not be explained by compromised cardiopulmonary function or other causes. One hundred and fifty-eight patients (38.3\%) had viral etiologies confirmed by PCR. HSV was detected in the CSF of 43 patients (27.2 \%) (23 encephalitis and 20 meningitis). Among the $23 \mathrm{HSE}$ patients; there was a slight female predominance (1.3:1), ages ranged between 1 and 85 years [17 (73.9\%) between 16 and 60 (an average of 36)]. Most of HSE patients were previously healthy except $2(8.7 \%)$ with diabetes, 2 (8.7 \%) hematologic malignancies, 1 (4.3\%) inactive SLE, 1 (4.3\%) multiple sclerosis (MS) and 1 (4.3\%) seropositive for human immune deficiency virus (HIV). Most of the patients were from central Thailand. The patient with HIV infection was diagnosed after hospitalization with acute HSE. Prior to hospitalization, the patient had been in good health, never received any highly active antiretroviral therapy (HAART), and did not have any opportunistic infection. The patient's CD4 count was 200 cells $/ \mathrm{mm}^{3}$. The patient with MS was in remission and received $50 \mathrm{mg}$ of azathioprine daily. Lastly, the patient with inactive SLE had mild thrombocytopenia, but was not on any immunosuppressive drugs or corticosteroids.

\section{Clinical findings}

Of 23 HSE patients, 16 cases $(69.6 \%)$ had fever as a prodrome. The most common presenting symptoms were seizures $(7 / 23,30.4 \%)$, behavioral changes $(6 / 23,26 \%)$, alteration of consciousness $(5 / 23,21.7 \%)$, focal neurological deficits $(3 / 23,13 \%)$, and worsening of headaches $(2 / 23,8.7 \%)$. All patients received intravenous administration of acyclovir. Six patients (26.1\%) recovered completely (The Modified Rankin Scale: mRS 0-1), 14 (60.9\%) partially recovered (mRS 2-3), and 3 patients (13\%) died. Demographic data, underlying diseases, and presenting symptoms of each group, classified according to CSF WBC count, are presented in Table 1.

\section{Laboratory findings}

All 23 cases had serum creatinine in the range of $0-3 \mathrm{mg} /$ $\mathrm{dl}$ and normal liver function test. Complete blood count data was available in 20 patients, of whom 14 (70 \%) were within the normal limit, 1 (5\%) had pancytopenia (patient no. 17 in pleocytosis group), and 1 (5\%) had leucopenia (patient no. 6 in normocellular group). Seventeen of 23 patients (73.9\%) had CSF examination within 2-10 days after neurological symptoms onset, the golden period for CSF PCR examination for HSV [7]. CSF findings are detailed in Table 2. CSF protein levels ranged between 14 and $528 \mathrm{mg} / \mathrm{dl}$ (mean $108.3 \mathrm{mg} / \mathrm{dL}$ ), while CSF glucose levels were between 30 and $139 \mathrm{mg} / \mathrm{dl}$ (mean $66.2 \mathrm{mg} / \mathrm{dl})$. Seventeen patients $(73.9 \%)$ had CSF WBC counts between 6 and 500 cells $/ \mathrm{mm}^{3}$, with lymphocytic predominance.

Six cases (26.1\%), with CSF examinations within 10 days after onset of illness (an average of 3 days), had normal CSF WBC $\left(<5\right.$ cells $\left./ \mathrm{mm}^{3}\right)$. One patient in this normocellular CSF group (16.7 \%) had HIV infection. Although this patient had low CD4 counts $(<200$ cells/ $\mathrm{mm}^{3}$ ), the peripheral WBC counts were 3150 and 3570 cells $/ \mathrm{mm}^{3}$ in two consecutive tests.

Seventeen patients had CSF pleocytosis with CSF WBC ranging between 15 and 730 cells (mean 179 cells $/ \mathrm{mm}^{3}$ ), 3 of whom had CSF WBC count greater than 500 cells/ $\mathrm{mm}^{3}$. Thirteen patients $(76.5 \%)$ were previously healthy. None of them had HIV infection. CSF HSV viral load in 
Table 1 Demographic data and presenting symptoms of HSV encephalitis in patients with CSF pleocytosis and patients with normocellular CSF

\begin{tabular}{|c|c|c|}
\hline Demographic data & $\begin{array}{l}\text { CSF pleocy- } \\
\text { tosis group } \\
\left(\text { WBC }>5 \text { cells } / \mathrm{mm}^{3}\right)\end{array}$ & $\begin{array}{l}\text { Normocellu- } \\
\text { lar CSF group } \\
\left(\text { WBC } \leq 5 \text { cells } / \mathrm{mm}^{3}\right)\end{array}$ \\
\hline Number of patients & 17 & 6 \\
\hline Male:female & $9: 8$ & $1: 5$ \\
\hline Median age (years) [range] & $35[1-59]$ & $41[27-85]$ \\
\hline \multicolumn{3}{|l|}{ Underlying disease } \\
\hline Normal & $13(76.5 \%)$ & $3(50 \%)$ \\
\hline HIV infection & 0 & $1(16.7 \%)$ \\
\hline Diabetes mellitus & $2(11.8 \%)$ & 0 \\
\hline Hematologic malignancy & $2(11.8 \%)$ & 0 \\
\hline Multiple Sclerosis (MS) & 0 & $1(16.7 \%)$ \\
\hline $\begin{array}{l}\text { Systemic Lupus Erythema- } \\
\text { tosus (SLE) }\end{array}$ & 0 & $1(16.7 \%)$ \\
\hline \multicolumn{3}{|l|}{ Prodrome } \\
\hline Fever & $1(5.9 \%)$ & $1(16.7 \%)$ \\
\hline Fever with headache & $9(52.9 \%)$ & $1(16.7 \%)$ \\
\hline Fever with myalgia & $1(5.9 \%)$ & $1(16.7 \%)$ \\
\hline $\begin{array}{l}\text { Upper respiratory tract } \\
\text { symptoms }\end{array}$ & $1(5.9 \%)$ & 0 \\
\hline Fever with diarrhea & $1(5.9 \%)$ & 0 \\
\hline $\begin{array}{l}\text { Fever with non-specific } \\
\text { rash }\end{array}$ & $1(5.9 \%)$ & 0 \\
\hline Headache & $2(11.8 \%)$ & 0 \\
\hline Non-specific & $1(5.9 \%)$ & $3(50 \%)$ \\
\hline \multicolumn{3}{|l|}{ Presenting symptoms } \\
\hline $\begin{array}{l}\text { Worsening headache } \\
\text { with/without neck } \\
\text { stiffness }\end{array}$ & $2(11.8 \%)$ & 0 \\
\hline Hemiparesis & $1(5.9 \%)$ & 0 \\
\hline Facial weakness & $1(5.9 \%)$ & 0 \\
\hline $\begin{array}{l}\text { Severe spastic body and } \\
\text { limbs }\end{array}$ & $1(5.9 \%)$ & 0 \\
\hline $\begin{array}{l}\text { Behavioral change and } \\
\text { confusion }\end{array}$ & $4(23.5 \%)$ & $3(50 \%)$ \\
\hline Seizures & $5(29.4 \%)$ & $2(33.3 \%)$ \\
\hline $\begin{array}{l}\text { Alteration of conscious- } \\
\text { ness }\end{array}$ & $3(17.6 \%)$ & $1(16.7 \%)$ \\
\hline \multicolumn{3}{|l|}{ Outcome } \\
\hline Complete recovery & $5(29.4 \%)$ & $1(16.7 \%)$ \\
\hline Partial recovery & $10(58.8 \%)$ & $4(66.7 \%)$ \\
\hline Dead & $2(11.8 \%)$ & $1(16.7 \%)$ \\
\hline
\end{tabular}

this group was higher than the normocellular group, with an average of $12,200 \mathrm{vs} 3027$ copies/ $\mathrm{ml}$ respectively. Of all 14 specimens received after 2007, 10 cases (2 normocellular, 8 pleocytosis) were positive for HSV1 and 4 cases (1 normocellular, 3 pleocytosis) were positive for HSV2 encephalitis. Other CSF parameters are described in Table 2.

\section{Imaging findings}

Twenty-two patients had complete neuroimaging (either computer tomography (CT) or MRI) records. Eleven (50\%) patients had the predominant temporal or frontotemporal lobe lesions and 2 (9.1\%) had fronto-temporal lesion coexisting with thalamic lesions. Another two patients had cortical/subcortical (non fronto-temporal) lesions. Two patients $(9.1 \%)$ had bead-like appearance resembling vasculitis on MR angiography, whereas 5 $(22.7 \%)$ had normal or non-specific findings. Brain imaging data altogether with CSF HSV viral load of normocellular and pleocytosis groups are presented in Tables 3 and 4 .

\section{Discussion}

In this study, 6 of 23 HSE patients (26.1\%) had normal CSF WBC counts as shown in Tables 1 and 2. All normocellular patients had CSF protein levels less than $100 \mathrm{mg} / \mathrm{dl}$, whereas half of the patients in the pleocytosis group had CSF protein levels greater than $100 \mathrm{mg} /$ dl. All brain MRIs of the 15 patients in the pleocytosis group, and 2 of 4 patients in the normocellular group showed abnormal lesions. Two normocellular patients had normal brain MRI and high viral load, 5970 and 3144 copies $/ \mathrm{ml}$ respectively. One of them had inactive SLE with drowsiness, while the other had MS (in remission) with behavioral change (Table 4). Two patients in the normocellular group had CT scan, which might not have been sensitive enough to detect abnormalities, as compared to MRI. However, both did not have any other explainable causes. There was no data on CSF HSV viral load in both cases as only qualitative PCR data was available. One patient was first diagnosed as HIV positive at the time of admission with HSE, with no history of previous opportunistic infections. HIV viral load was not performed in the CSF and data on viral load in the blood was not available. Although HIV encephalitis could not be excluded, such acute presentation suggests otherwise. Retrospective autoantibody test was negative. Both patients had partial recovery with acyclovir treatment.

Our study showed that HSE with normocellular CSF is more common than what was generally known in the past. The CSF protein levels, number of cases with abnormal neuroimaging, and CSF viral loads in the pleocytosis group were higher when compared to the normocellular group. It was noted that CSF viral load was up to four times higher in CSF pleocytosis group than normocellular group (an average of 12,200 vs 3027 copies $/ \mathrm{ml}$ ), potentially due to increased inflammatory response in pleocytosis group. Viral load alone may not entirely explain the magnitude of CSF cellular response, as patients with nonspecific MRI in the normocellular 
Table 2 CSF profiles and imaging findings

\begin{tabular}{|c|c|c|}
\hline CSF Profile & $\begin{array}{l}\text { CSF pleocytosis group } \\
\left(\mathrm{WBC}>5 \text { cells } / \mathrm{mm}^{3}\right)\end{array}$ & $\begin{array}{l}\text { Normocellular CSF group } \\
\left(\mathrm{WBC} \leq 5 \mathrm{cells} / \mathrm{mm}^{3}\right)\end{array}$ \\
\hline Days of CSF examination after neurological onset & $\begin{array}{l}\text { Day } 0-1: 5(29.4 \%) \\
\text { Day } 2-10: 12(70.6 \%)\end{array}$ & $\begin{array}{l}\text { Day 0-1: } 1(16.7 \%) \\
\text { Day 2-10: } 5(83.3 \%)\end{array}$ \\
\hline CSF protein & $\begin{array}{l}\text { 0-60 mg/dl: } 1 \text { (6.3 \%) } \\
\text { 61-100 mg/dl: } 7 \text { (43.8\%) } \\
\text { >100 mg/dl: } 8 \text { (50 \%) } \\
\text { Not available: } 1\end{array}$ & $\begin{array}{l}0-60 \mathrm{mg} / \mathrm{dl}: 2 \text { (33.3 \%) } \\
61-100 \mathrm{mg} / \mathrm{dl}: 4(66.7 \%) \\
>100 \mathrm{mg} / \mathrm{dl}: 0\end{array}$ \\
\hline CSF glucose & $\begin{array}{l}<30 \text { mg/dl: } 1 \text { (6.3\%) } \\
\text { 31-60 mg/dl: } 7 \text { (43.8 \%) } \\
\text { >60 mg/dl: } 8 \text { (50 \%) } \\
\text { Not available: } 1\end{array}$ & $\begin{array}{l}<30 \mathrm{mg} / \mathrm{dl}: 0 \\
31-60 \mathrm{mg} / \mathrm{dl} 1(16.7 \%) \\
>60 \mathrm{mg} / \mathrm{dl}: 5(83.3 \%)\end{array}$ \\
\hline Average CSF viral load & $\begin{array}{l}\text { 12,200 copies/ml (39-11,755,813 } \\
\text { copies/ml) ( } 11 \text { cases available: } \\
6 \text { had qualitative test) }\end{array}$ & $\begin{array}{l}3027 \text { copies/ml } \\
\text { (59-5970 copies/ml) } \\
\text { (4 cases available: } 3 \text { had qualitative test) }\end{array}$ \\
\hline Brain imaging findings & 16 available records & 6 available records \\
\hline Predominant temporal lobe lesions & $5(29.4 \%)$ & $1(16.7 \%)$ \\
\hline Fronto-temporal lesions & $4(23.5 \%)$ & $1(16.7 \%)$ \\
\hline Other cortical and subcortical lesions (non fronto-temporal) & $3(18.8 \%)$ & 0 \\
\hline Fronto-temporal and thalamic lesions ${ }^{\mathrm{a}}$ & $3(18.8 \%)$ & 0 \\
\hline Normal or Miscellaneous ${ }^{b}$ & 0 & $2(33.3 \%)$ \\
\hline Normal CT (MRI not performed) & $1(5.9 \%)$ & $2(33.3 \%)$ \\
\hline
\end{tabular}

a Two of the patients (a non fronto-temporal lesion and one with fronto-temporal and thalamic lesions) also had vasculitis, visualized using magnetic resonance angiography

b Miscellaneous refers to non-specific lesions such as non-specific white matter changes, aging brain etc

Table 3 Individualized data of the CSF pleocytosis group of HSE patients

\begin{tabular}{|c|c|c|c|c|c|}
\hline Patient no. & Underlying disease & $\begin{array}{l}\text { CSF WBC } \\
\text { (cells } / \mathrm{mm}^{3} \text { ) }\end{array}$ & Imaging pattern (MRI) & $\begin{array}{l}\text { CSF HSV viral load } \\
\text { (copies/ml) }\end{array}$ & Outcome \\
\hline 1 & Normal & 230 & Fronto-temporal lesions & 16,975 & Complete recovery \\
\hline 2 & Normal & 350 & Fronto-temporal lesions & 2214 & Complete recovery \\
\hline 3 & Normal & 70 & Fronto-temporal lesions & Qualitative PCR & Complete recovery \\
\hline 4 & Normal & 730 & Temporal lobe lesions & $11,755,813$ & Partial recovery \\
\hline 5 & Normal & 22 & Fronto-temporal and thalamic lesions & 500,000 & Partial recovery \\
\hline 6 & Normal & 90 & Temporal lobe lesions & 71,875 & Complete recovery \\
\hline 7 & Hematologic malignancy & 147 & Temporal lobe lesions & 30,750 & Complete recovery \\
\hline 8 & Normal & 75 & Fronto-temporal and thalamic lesions & 12,200 & Partial recovery \\
\hline 9 & DM & 510 & Other cortical and subcortical lesions & 3325 & Dead \\
\hline 10 & Normal & 40 & Normal CT & 1491 & Partial recovery \\
\hline 11 & Hematologic Malignancy & 40 & Other cortical and subcortical lesions & 740 & Dead \\
\hline 12 & Normal & 60 & Fronto-temporal and thalamic lesions & 39 & Partial recovery \\
\hline 13 & DM & 15 & N/A & Qualitative PCR & Partial recovery \\
\hline 14 & Normal & 600 & Temporal lobe lesions & Qualitative PCR & Partial recovery \\
\hline 15 & Old ischemic stroke & 22 & Fronto-temporal lesions & Qualitative PCR & Partial recovery \\
\hline 16 & Normal & 30 & Temporal lobe lesions & Qualitative PCR & Partial recovery \\
\hline 17 & Normal & 20 & Other cortical and subcortical lesions & Qualitative PCR & Partial recovery \\
\hline
\end{tabular}

group also had high copies of viral load. When looking at individual data in normocellular group (Table 4), the patient with the highest viral load (5970 copies/ ml) had normal MRI and CSF protein level of $14 \mathrm{mg} /$ dl. Why some HSE patients have normocellular CSF, or normal/nonspecific MRI remains a mystery. Whether 
Table 4 Individualized data of the normocellular CSF group of HSE patients

\begin{tabular}{|c|c|c|c|c|c|}
\hline Patient no. & Underlying disease & $\mathrm{CBC}$ & Imaging pattern (MRI) & CSF HSV viral load (copies/ml) & Outcome \\
\hline 1 & Systemic Lupus Erythematosus & Thrombocytopenia & Normal MRI & 5970 & Dead \\
\hline 2 & Multiple Sclerosis & Normal & Old white matter lesions & 3144 & Partial recovery \\
\hline 3 & Normal & Leukocytosis & Fronto-temporal lesion & 2910 & Complete recovery \\
\hline 4 & Normal & Normal & Temporal lobe lesion & 59 & Partial recovery \\
\hline 5 & Normal & Normal & Normal CT & Qualitative PCR & Partial recovery \\
\hline 6 & HIV infection & Leukopenia & Normal CT & Qualitative PCR & Partial recovery \\
\hline
\end{tabular}

viral load and/or genetic factors influence inflammatory responses in the CSF or abnormal MRI findings is not yet known. Moreover, viral load may not affect the outcome, as patients in normocellular group with lower viral load were, in fact, more inclined to be more severely affected by the disease (one died, four partially recovered, one complete recovery) compared to the pleocytosis group, which had higher viral loads on average (two died, ten partially recovered, five complete recovery). This conformed to a previous study which reported no correlation between CSF viral load and clinical outcome in HSE patients [21]. Further study in the CSF of HSE patients which compares the inflammatory responses in both pleocytosis and normocellular group is needed to elucidate the pathophysiology of HSE.

A retrospective study of 35 HSE patients in Spain over a 15 year period revealed that $8(22.8 \%)$ had normal CSF WBC counts [26]. However, all patients in this Spanish study had neuroimaging abnormalities but only $92 \%$ of patients had PCR positive for HSV. Furthermore, a large encephalitis study in Turkey, which recruited 106 patients between 2001 and 2012, revealed approximately $15 \%$ of HSE patients had acellular and normocellular CSF [5]. The Turkish study also revealed that as many as $5 \%$ had no MRI lesions.

Our study had some limitations, such as small sample size, and lack of complete data in some subjects. However, the study also revealed important data that directly affects the clinical management of HSE. An absence of CSF pleocytosis and/or MRI abnormalities does not exclude infectious encephalitis, in particular HSE. Additionally, examination of HSV DNA by PCR in the CSF is mandatory in the management of encephalitis. Our study indicates that relying on the CSF pleocytosis and/ or presence of classical MRI features of HSE may result in a delay in diagnosis and treatment. A larger study is further required to confirm results statistically and analyze inflammatory responses in normocellular HSE, when compared to pleocytosis group, to better understand the pathophysiology of HSE.

\section{Conclusion}

Absence of CSF pleocytosis in HSE has been described as a rare finding in the past, which can distract physicians from the veritable diagnosis. Our study intended to demonstrate the extent to which normal CSF WBC findings are found in encephalitis associated with HSV. It is not uncommon, and can be found in previously healthy patients. Therefore, clinicians should not exclude CNS infection (especially HSE) based on the absence of CSF pleocytosis and normal neuroimaging.

\section{Abbreviations}

CD4: cluster of differentiation 4; CMV: Cytomegalovirus; CNS: central nervous system; CSF: cerebrospinal fluid; CT: computed tomography; DNA: deoxyribonucleic acid; EBV: Epstein-Barr virus; HIV: Human immunodeficiency virus; HSE: Herpes simplex encephalitis; HSV: Herpes simplex virus; IFN: interferon; IRB: Institutional Review Board; IRF: interferon regulatory factor; KCMH: King Chulalongkorn Memorial Hospital; MR: magnetic resonance; MRI: magnetic resonance imaging; MS: multiple sclerosis; NMDA: N-methyl-D-aspartate; PCR: polymerase chain reaction; SLE: systemic lupus erythematosus; TANK: TRAF family member-associated NFKB activator; TBK1:TANK-binding kinase 1; TIR: toll-interleukin 1 receptor; TLR: toll-like receptors; TNF: tumour necrosis factor; TRAF3: TNF receptor associated factors; TRIF: TIR-domain-containing adapterinducing interferon- $\beta$; UNC93B1: Unc-93 homolog B1; VZV: Varicella zoster virus; WBC: white blood cell.

\section{Authors' contributions}

AS and TH participated in patient management. AS carried out data collection, interpretation of the data and prepared draft for the manuscript. TH participated in design, interpretation of the data and reviewed the manuscript to final version. SW and SP participated in PCR diagnosis. NS performed the immunofluorescence laboratory assay. HW and SG contributed to and edited the manuscript. All authors read and approved the final manuscript.

\section{Author details}

${ }^{1}$ WHO-CC for Research and Training on Viral Zoonoses, Division of Neurology, Department of Medicine, Faculty of Medicine, Neuroscience Centre for Research and Development, Chulalongkorn University and King Chulalongkorn Memorial Hospital, Rama 4 Road, Pathumwan, Bangkok 10330, Thailand. ${ }^{2}$ Division of Infectious Disease, Department of Medicine, Faculty of Medicine, Chulalongkorn University and King Chulalongkorn Memorial Hospital, Bangkok, Thailand.

\section{Acknowledgements}

This work was part of the encephalitis project in Thailand supported by grants from a Broad Agency Agreement with the Naval Health Research Center (NHRC) under Cooperative Agreement Number W91 1 NF-1 1-2-0041. It was sponsored by the Research Chair Grant from the National Science and Technology Development Agency (NSTDA) (Thailand). We also thank Michael V. Callahan MD, DTM\&H. MSPH. For reviewing this manuscript. 


\section{Competing interests}

The authors declare that they have no competing interests.

Received: 10 July 2015 Accepted: 8 February 2016

Published online: 15 February 2016

\section{References}

1. Kennedy PG, Steiner I. Recent issues in herpes simplex encephalitis. J Neurovirol. 2013;19(4):346-50.

2. Lim HK, et al. TLR3 deficiency in herpes simplex encephalitis: high allelic heterogeneity and recurrence risk. Neurology. 2014;83(21):1888-97.

3. Granerod J, et al. Causes of encephalitis and differences in their clinical presentations in England: a multicentre, population-based prospective study. Lancet Infect Dis. 2010;10(12):835-44.

4. Koskiniemi M, et al. Herpes encephalitis is a disease of middle aged and elderly people: polymerase chain reaction for detection of herpes simplex virus in the CSF of 516 patients with encephalitis. The Study Group. J Neurol Neurosurg Psychiatry. 1996;60(2):174-8.

5. Whitley RJ, et al. Vidarabine versus acyclovir therapy in herpes simplex encephalitis. N Engl J Med. 1986;314(3):144-9.

6. Solomon T, et al. Management of suspected viral encephalitis in adultsAssociation of British Neurologists and British Infection Association National Guidelines. J Infect. 2012;64(4):347-73.

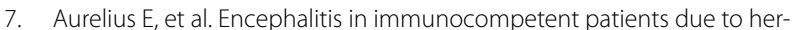
pes simplex virus type 1 or 2 as determined by type-specific polymerase chain reaction and antibody assays of cerebrospinal fluid. J Med Virol. 1993;39(3):179-86.

8. Moon SM, et al. Comparison of clinical manifestations, outcomes and cerebrospinal fluid findings between herpes simplex type 1 and type 2 central nervous system infections in adults. J Med Virol. 2014;86(10):1766-71.

9. Mateen FJ, Miller SA, Aksamit AJ Jr. Herpes simplex virus 2 encephalitis in adults. Mayo Clin Proc. 2014;89(2):274-5.

10. Barnett EM, et al. Herpes simplex encephalitis in the temporal cortex and limbic system after trigeminal nerve inoculation. J Infect Dis. 1994;169(4):782-6.

11. Whitley RJ, et al. Adenine arabinoside therapy of biopsy-proved herpes simplex encephalitis. National Institute of Allergy and Infectious Diseases collaborative antiviral study. N Engl J Med. 1977;297(6):289-94.

12. Tyler KL. Herpes simplex virus infections of the central nervous system: encephalitis and meningitis, including Mollaret's. Herpes. 2004;11(Suppl 2):57A-64A.
13. Baringer JR. Herpes simplex infections of the nervous system. Neurol Clin. 2008;26(3):657-74 (viii)

14. Baringer JR, Pisani P. Herpes simplex virus genomes in human nervous system tissue analyzed by polymerase chain reaction. Ann Neurol. 1994;36(6):823-9.

15. Domingues RB, et al. Evaluation of the range of clinical presentations of herpes simplex encephalitis by using polymerase chain reaction assay of cerebrospinal fluid samples. Clin Infect Dis. 1997;25(1):86-91.

16. Kennedy PG, Chaudhuri A. Herpes simplex encephalitis. J Neurol Neurosurg Psychiatry. 2002;73(3):237-8.

17. Whitley RJ, Gnann JW. Viral encephalitis: familiar infections and emerging pathogens. Lancet. 2002;359(9305):507-13.

18. Steiner I, Tyler KL. The toll (like receptor 3 ) to the pathogenesis of herpes simplex encephalitis. Neurology. 2014;83(21):1882-3.

19. Steiner I, et al. EFNS-ENS guidelines for the use of PCR technology for the diagnosis of infections of the nervous system. Eur J Neurol. 2012;19(10):1278-91.

20. Lafaille FG, et al. Impaired intrinsic immunity to HSV-1 in human iPSCderived TLR3-deficient CNS cells. Nature. 2012;491(7426):769-73.

21. Desena A, et al. Herpes simplex encephalitis as a potential cause of anti$\mathrm{N}$-methyl-D-aspartate receptor antibody encephalitis: report of 2 cases. JAMA Neurol. 2014;71(3):344-6.

22. Gkrania-Klotsas E, Lever AM. Herpes simplex I encephalitis presenting as a brain haemorrhage with normal cerebrospinal fluid analysis: a case report. J Med Case Rep. 2008;2:387.

23. Mook-Kanamori B, van de Beek D, Wijdicks EF. Herpes simplex encephalitis with normal initial cerebrospinal fluid examination. J Am Geriatr Soc 2009;57(8):1514-5.

24. Schoonman GG, et al. Herpes simplex virus encephalitis without cerebrospinal fluid pleocytosis is not unusual. J Am Geriatr Soc. 2012;60(2):377-8.

25. Kessler $\mathrm{HH}$, et al. Detection of Herpes simplex virus DNA by real-time PCR. J Clin Microbiol. 2000;38(7):2638-42.

26. Riera-Mestre A, et al. Adult herpes simplex encephalitis: fifteen years' experience. Enferm Infecc Microbiol Clin. 2009;27(3):143-7.

\section{Submit your next manuscript to BioMed Central and we will help you at every step:}

- We accept pre-submission inquiries

- Our selector tool helps you to find the most relevant journal

- We provide round the clock customer support

- Convenient online submission

- Thorough peer review

- Inclusion in PubMed and all major indexing services

- Maximum visibility for your research

Submit your manuscript at www.biomedcentral.com/submit
() Biomed Central 